\title{
Social Networking Site Continuance: The Paradox of Negative Consequences and Positive Growth
}

\author{
Gina Harden, Sherry D. Ryan, and Victor R. Prybutok \\ University of North Texas, Denton, TX, USA
}

\author{
gina.harden@unt.edu; sherry.ryan@unt.edu; \\ victor.prybutok@unt.edu
}

\begin{abstract}
The growth of social networking sites (SNSs) introduces a variety of interesting behaviors by users of these online informing environments. SNSs have become important informing channels for both personal and commercial interests, but paradoxically some experience enormous growth even when unfavorable consequences are continually reported, while others decline. This research investigates new factors influencing SNS satisfaction and continuance intention. A survey given to college students in a North American university using sites like Facebook or MySpace was used to examine satisfaction and continuance intention based on transdisciplinary theories of technology acceptance and satisfaction, with the addition of two new constructs. The results indicate that authority figure users have a negative moderating effect on satisfaction, while resistance to change positively affects continuance intention, even in the face of such dissatisfaction. Limitations of the study include the use of only North American students as subjects. Therefore, cultural issues and the use of a student sample make the results inapplicable to the general population. The results of the study help explain why some SNS environments might enjoy growth and popularity even as others fail, extending the literature on continuance intention and also providing implications for practitioners.
\end{abstract}

Keywords: Social networking sites, informing channel, continuance intention, authority figures, resistance to change

\section{Introduction}

According to the informing science framework put forth by Cohen (2009), an Informing System is composed of three elements: the informing environment, the delivery system, and the taskcompletion system. The current study investigates the informing environment of SNS users, where the delivery system includes online social media tools that facilitate the task-completion activities of sharing personal information and interacting with contacts while extending one's personal network. Of interest to transdisciplinary research are the sometimes unintended conse-

Material published as part of this publication, either on-line or in print, is copyrighted by the Informing Science Institute. Permission to make digital or paper copy of part or all of these works for personal or classroom use is granted without fee provided that the copies are not made or distributed for profit or commercial advantage AND that copies 1) bear this notice in full and 2) give the full citation on the first page. It is permissible to abstract these works so long as credit is given. To copy in all other cases or to republish or to post on a server or to redistribute to lists requires specific permission and payment of a fee. Contact Publisher@InformingScience.org to request redistribution permission. quences of using an SNS informing system and the effect of those consequences on satisfaction and continuance intention of SNS users.

The growth of various social networking sites such as Facebook, MySpace, and Twitter offers informers an easy and efficient delivery system for informing clients through a diverse set of informing channels such as personal profiles, 
newsfeeds, chat, and sharing of media including pictures, audio and video. The ability of SNS users to post user-generated content allows the informer and the client to adopt interchangeably each role as the information is either shared by the informer or received by the client. As Birdsall (2009) noted, the missing component of the informing science framework is the right of the client not only to be informed but also to inform. Thus, the informer and the client are engaged in a collaborative effort in creating the online informing system of an SNS.

This simultaneous sharing and receiving of information has led to a growth in social networking sites. These sites offer a "free and immensely powerful set of communication and collaboration tools to everyone of Earth who has access to a broadband internet connection" ("Towards a socialized state," 2010). Of interest is the tremendous growth for some of those sites, while others have seen their user base dwindle or even disappear. The digital marketing intelligence group comScore reported that in the month of April 2009 social networking sites experienced record growth in the US with an increase of $12 \%$ usage, or nearly 140 million users in that month alone, with MySpace having 71 million US visitors followed by Facebook with 67 million visitors (comScore, 2009). However, while the two SNSs were relatively close in terms of numbers at that point in time, Facebook continued to surge in popularity while MySpace experienced a steady decline in members.

Facebook began in 2004 with one million users by the end of its first year and grew to five million users by the end of its second year (Facebook Company Info, 2005). Facebook continued to experience a surge in growth reaching over half a billion users by 2010 and 845 million users by 2011 (Facebook Company Info, 2011). MySpace experienced similar extraordinary growth initially, from one million members in January 2004 to over 5 million by the end of their first year, and over 100 million users by March 2007 (TechCrunch, n.d.). Originally developed to attract disgruntled Friendster users, MySpace grew rapidly in large part due to independent bands working to connect with their fans, largely a younger crowd (Boyd \& Ellison, 2007). Boyd and Ellison (2007) reported that Friendster itself was an SNS that experienced strong growth initially, but then failed to keep up with the demand placed on its servers and databases. Ultimately user preferences were not met, thus Friendster lost its foothold in the U.S. The authors note that "because organic growth had been critical to creating a coherent community, the onslaught of new users who learned about the site from media coverage upset the cultural balance" (Boyd \& Ellison, 2007, p. 214).

Just as Friendster gained then lost, MySpace also experienced rapid declines in its user base, laying off almost one-third of its employees in 2009 (Arango, 2009) and another 47\% of the remaining employees in January 2011 (Arango, 2011). The latest misfortune for the once popular SNS came in the summer of 2011 when News Corporation, parent company of MySpace, sold the failing SNS for only \$35 million after acquiring it in 2005 for \$580 million (Stelter, 2011). Even online giant Google experienced a failure with its initial entry into the social networking arena, Google Buzz. The company reached a settlement with the US Federal Trade Commission in 2010 as a result of charges that Google was violating its own privacy policies and agreed to twenty years of privacy policy audits by the government (Sullivan, 2011). Undaunted, Google is trying again with Google+ and is experiencing a surging growth with its latest SNS offering, going from 40 million users in October 2011 to over 90 million in January 2012 (Milian, 2012).

Not only must developers of these online systems deal with the logistical challenges of rapidly increasing user traffic and rapidly changing user preferences, but they also must be aware of users' satisfaction with and intention to continue to use their SNS. If they do not pay close attention to their users' requirements, whether in the form of enhanced services, privacy concerns, or simply the right informing environment, developers of SNSs can watch their creation die a death as rapid as some sites' meteoric rise to success. The Hub, a social networking site created by WalMart for teen users died only a few months after its inception, possibly because there were too 
many blatant advertisements incorporated into the site by the giant retailer. There was also a surprising failure of Yahoo's attempt at entering the SNS market with the decline and eventual failure of Yahoo 360.

The failure of such big corporate names, some already big players in providing online services, points to the critical need of a SNS provider to understand user preferences, requirements, and satisfaction in order to both gain and retain those users. Understanding why there is steady growth for some SNSs while others experience wild swings in user satisfaction calls for a new lens of theoretical inquiry to examine the phenomena of SNS user behaviors. In the current authors' opinions, current IS models of user satisfaction and continuance intentions are insufficient to explain the behaviors of SNS users in an environment that sometimes offers conflicting rewards as a result of use. These previous models do not consider important contextual variables specific to SNS use such as authority figures, which are SNS users with the authority to exert disciplinary action such as parents, school administrators, law enforcement, or potential employers, using the SNS. Issues of privacy and security of one's personal information mix with the ability to interact, share, and extend one's personal network of friends. The tremendous growth in the number of new users has created a changing demographic of the average user, as previously mentioned, and in the way SNSs are being used.

While the growth of some SNSs is well documented, what remains a mystery is why an SNS such as Facebook continues to grow in spite of news articles that report negative consequences from using the site such as employees being fired for posting inappropriate pictures or students punished for violating their school's conduct policies as a result of postings on their Facebook or MySpace pages. A Google search for "student suspended for facebook" returns over 6,000 results. A similar search for "employee fired for facebook" returns over 18,000 results.

For instance, a North Carolina college student was suspended two semesters for posting his displeasure about the school's debit card on his Facebook account ("Student suspended over Facebook post," 2011). Another case reports a student suspended five days for posting critical comments about a teacher on his Facebook page, leaving his parents considering a lawsuit (Greiner, 2010). Other situations involve potential employers requesting sites and login information of job applicants for screening purposes. In a study commissioned by Microsoft, the research firm Crosstab found that seventy percent of recruiters and HR professionals say they have rejected candidates based on information they found online (Cross-Tab, 2010).

What happens when users are concerned about what they post as an informer that might be delivered inadvertently to an unintended client? Proofpoint reports that eight percent of U.S. companies with 1,000 or more employees dismissed someone for their behavior on SNSs in 2009. This was double the number from 2008, and seventeen percent reported having issues with employees' use of social media (Proofpoint, 2009). Users have been fired from their employment due to inappropriate postings about their beliefs or activities.

One situation involves a young employee, new on the job and complaining about the work circumstances on her personal Facebook page, being summoned into her boss' office and fired on the spot (Levy, 2009). The young worker was shocked as she had posted the comments on a personal page and did not intend for anyone else to be able to see them, especially her employer. Law enforcement officials have browsed Facebook pages to find or confirm evidence against users and press charges as a result, as was the case in Michigan when seventy-four suspected gang members were arrested partly based on information posted on the suspects' Facebook pages ("Facebook helps police arrest 74," 2010). Some of these issues have already made their way into the legal system as the parties involved attempt to determine what constitutes appropriate use.

To understand these trends more clearly, this study examines the influence of a perceived shift in the demographics toward more authority figure users on satisfaction with the SNS and, thus, the 
intention to continue to use the SNS. Additionally, if there is a negative effect from the perception of increasing authority figure users, how can the apparent conflict of continuance intentions remaining strong even when user satisfaction decreases be explained? To attempt to answer these issues, the current study proposes a conceptual model of SNS Continuance Intentions and two new constructs, authority figure users (AFU) and resistance to change (RTC).

This research suggests that as the perception of authority figure users on the site increases, the effect on satisfaction will be negatively moderated. However, even though users are dissatisfied with some of the new members or new uses on their site, they are satisfied with their overall experience enough to resist the negative effects and will continue to use that SNS. The sites of MySpace and Facebook are the only two being considered in this study, as a result of the survey responses collected, which list these two as the only favored SNSs of the individual respondents.

To the authors' knowledge, the constructs of authority figure users and resistance to change provide a new area of research not previously studied when investigating use of an online environment. While there has been some investigation regarding resistance in the IS literature, it has primarily focused on resistance to technology acceptance (Hess, Joshi, \& McNab, 2010; Joshi, 2005; Srivasta, 2011). Additionally, research on organizational management issues used Oreg's (2006) resistance to change model to assess ways to reduce employee resistance to change in the organization. However, the current study examines the intention to continue using an SNS even in the face of changes that might be deemed undesirable.

This paper contributes to informing science literature by introducing a new construct - AFU - to be investigated as developers of SNSs and online systems in general continue efforts to understand user satisfaction and intention to continue using SNSs. This research proposes that AFU has a negative moderating effect on user satisfaction with the SNS and that RTC has a positive influence on continuance intention, regardless of perceived dissatisfaction. The structure of the remainder of this paper is as follows. First, a review of the relevant literature on IT acceptance and satisfaction is presented, then the definition of constructs and theoretical model used in hypotheses development is given, followed by the discussion of methodology and the scale measure used to investigate the research questions. Finally, the data analysis is presented along with a discussion of the findings and implications, and suggestions are made for future research.

\section{Literature Review and Theoretical Framework}

An abundance of IS research investigates individual user behaviors regarding intention to use specific computer systems (Au, Ngai, \& Cheng, 2002; Bhattacherjee \& Premkumar, 2004; Brown, Venkatesh, Kuruzovich, \& Massey, 2008; Davis, 1989; van der Heijden, 2004). Much of the research stream draws from Davis' Technology Acceptance Model (TAM) and various adaptations of that model looking primarily at user acceptance of information systems determined by perceived ease of use and perceived usefulness (Davis 1989). There has also been considerable effort to study user satisfaction with an information system (Abdinnour-Helm, Chaparro, \& Farmer, 2005; Au et al., 2002; Chen, 2007; Kim, Ferrin, \& Rao, 2009; McKinney, Yoon, \& Zahedi, 2002; Wixom \& Todd, 2005) largely based on the Expectation-Confirmation Theory (ECT) originated by Oliver, (1977). ECT is based on the premise that expectations along with perceived performance either confirms or disconfirms satisfaction with the product (Bhattacherjee, 2001, Brown et al., 2008). The current research proposes a theoretical framework to assess satisfaction and continuance intention for an SNS based on a synthesis TAM and ECT theories.

Early research in IS satisfaction finds an association between users' expectations and their perception of satisfaction (Szajna \& Scammel, 1993). The study is based on cognitive dissonance theory, which says expectations are confirmed or disconfirmed, thus affecting performance and perceptions of satisfaction (Szajna \& Scammel, 1993). Calling their work exploratory, Szajna and 
Scammel (1993) called for further research in the development of an instrument to measure user expectations and, thus, better predict satisfaction. Further efforts to validate a scale to measure end-user satisfaction with a web site were tested by Abdinnour-Helm et al. (2005) as these authors conducted a study of determinants of satisfaction with a web site from a usability perspective. Similar efforts were undertaken to develop theoretically sound constructs to measure satisfaction of web site customers by McKinney et al. (2002).

While the current research is focused on both satisfaction and continuance intention of a SNS user, which is predominantly hedonic in context, the validation of scale items provided by the work of Abdinnour-Helm et al. (2005) and McKinney et al. (2002) is useful in adapting scale items to measure the construct of SNS users' satisfaction. Further, in a review of the literature on IS satisfaction, Au et al. (2002) find that ECT is the dominating theory used to research IS end-user satisfaction. The authors note the extensive use of satisfaction as a key determinant of IS success and its interchangeable use as a measure of effectiveness or success (Au et al., 2002). Thus, following the dominant research stream in the IS literature, this paper will focus largely on ECT to guide the conceptual framework of this research study.

In addition, user behaviors and attitudes such as satisfaction, perceived enjoyment, and continuance intentions for online informing environments provide the theoretical foundations of the current research framework (Bhattacherjee, 2001; Lin, Wu, \& Tsai, 2005; Sledgianowski \& Kulviwat, 2009; van der Heijden, 2004). The focus in these studies has been on the effect that various independent variables such as perceived enjoyment or perceived playfulness (used interchangeably), perceived ease of use, and confirmation (or disconfirmation) have on the dependent variables of individual users' behaviors regarding their satisfaction with and intention to use and to continue to use specific online computer systems (Bhattacherjee, 2001; van der Heijden, 2004). Some studies have also incorporated variables such as social norms, trust, and critical mass when investigating the intention to use an SNS (Sledgianowski \& Kulviwat, 2009).

The TAM model theorizes that a user's measure of perceived usefulness and perceived ease of use are determinants of both his or her intent to use and his or her actual usage of an information system (Davis, 1989). Bhattacherjee (2001) incorporates elements of TAM theory to study online banking systems and looks beyond mere satisfaction toward continuance intentions, extending both ECT and TAM, to develop a synthesized model from these theories, resulting in the IS Continuance model. The IS Continuance model suggests that an information system user's perception of usefulness is confirmed or disconfirmed which impacts satisfaction and thus, the user's intention to continue to use the system (Bhattacherjee, 2001). Bhattacherjee's (2001) seminal study investigates the continuance intentions of users of an online information system and finds empirical support for the IS Continuance model as well as providing an initial, validated scale for measuring IS continuance. Brahmasrene and Lee (2012) also incorporate elements of TAM in their examination of students' continuance intention for online learning environments.

Chen (2007) also focused on elements of ECT in investigating the determinants of members' continuance intentions in professional virtual communities. Chen finds empirical support for the theoretical framework of ECT when looking at a professional virtual network, which in many instances is similar to a SNS. The study finds a positive relationship between confirmation of expectations and satisfaction and, in turn, a positive association between satisfaction and continuance intentions (Chen, 2007). The research is conflicting, however, with Brown et al. (2008) finding no support for the disconfirmation model of ECT when comparing three different expectation confirmation models. The authors do find that a strong relationship exists between the independent variables of expectations and experiences and the dependent variable of satisfaction, especially when looking at an IS implementation (Brown et al., 2008), furthering supporting the current authors' use of ECT as a basis for examining user satisfaction with a SNS and the intention to continue to use that site. 
Vatanasombut, Igbaria, Stylianou, and Rodgers (2008) follow the research stream investigating continuance intentions of online environments by using an integrated framework based on elements of ECT and TAM merged with relationship issues of commitment and trust. The authors find a positive association exists among the added constructs of commitment and trust, but caution their results should be evaluated further, as the variables explained only $22 \%$ of the variance in IS continuance intention (Vatanasombut et al., 2008). Following the validated efforts of previous researchers in measuring satisfaction and continuance intentions, the current research synthesizes elements from ECT and the IS Continuance models to investigate the relationship that exists between students who are current users of a SNS and their satisfaction with and intention to continue using that SNS.

This paper also extends the research stream of online IS users' continuance intentions by recognizing that the hedonic system usage of SNSs examined in the current study introduces new elements that must also be considered in the investigation. The context of this study is the hedonic use of an SNS in which the value to a user is predominantly entertainment in nature, such as sharing one's status, photos, videos, or gaming activities as opposed to the utilitarian value of commercial or professional networking activities. When looking at the hedonic use of a SNS, Sledgianowski and Kulviwat (2009) find that the intrinsic motivator of perceived playfulness or enjoyment that one finds by using the system has the strongest impact on intent to use and actual use. Their investigation extends the research efforts initiated by van der Heijden (2004), who investigates the user acceptance of hedonic systems. van der Heijden (2004) finds, when studying the literature on acceptance and usage of information technology, that the predictors vary depending on the context in which the system is used, being either utilitarian or hedonic.

The research of van der Heijden (2004) shows that when determining the predictors for user acceptance of hedonic information systems, perceived enjoyment and perceived ease of use are stronger determinants of intention to use than perceived usefulness. Other researchers also find empirical support for the measure of perceived enjoyment or playfulness as a determinant of satisfaction and thus intent to reuse a web site (Lin et al., 2005). The results of the study by Lin et al. (2005) show that the relationship between perceived playfulness and satisfaction provide a much better fit than a direct path between perceived usefulness and satisfaction (Lin et al., 2005). The theoretical model in this paper will therefore use the construct of perceived playfulness identified by users of a SNS as a determinant of satisfaction with that site.

Like Bhattacherjee (2001), Bhattacherjee and Premkumar (2004), and many others, Sledgianowski and Kulviwat (2009) extend TAM theory and also add elements from the Unified Theory of Acceptance and Use of Technology (UTAUT) (Venkatesh, Morris, Davis, \& Davis, 2003), to develop their own Social Network Site Adoption model. Their research focuses on the hedonic context of the use of a SNS and incorporates social influences of critical mass, trust, and normative pressures from UTAUT along with the constructs of playfulness, perceived ease of use, and perceived usefulness to develop their model of SNS adoption (Sledgianowski \& Kulviwat, 2009). As the intention of the current research is to look beyond mere acceptance of a SNS and toward continuance intentions, this paper proposes an ongoing synthesis of existing IS theory by integrating elements of Bhattacherjee's IS Continuance model with the Social Network Site Adoption model of Sledgianowski \& Kulviwat (2009).

\section{Conceptual Model and Hypotheses}

The conceptual model for this study is synthesized from previous IS theories mentioned above that examine acceptance, satisfaction, and continuance intentions of online IS users and, in particular, founded on the IS Continuance model (Bhattacherjee, 2001) and the Social Network Site Adoption model (Sledgianowski \& Kulviwat, 2009). Though myriad independent variables have been used in attempts to determine satisfaction and continuance intention, it is the authors' belief 
that adherence to parsimonious theoretical model building will further enhance the exploratory nature of the new independent construct presented in this paper, resistance to change (RTC), as well as the new moderating construct proposed, authority figure users (AFU). As the use of social networking sites is relatively new, many of the behaviors associated with their use are fairly recent as well, calling for novel methods of measuring perceptions and motivations of SNS users. Figure 1 below presents the integrated SNS Continuance Intention model providing the framework that represents the relationships investigated in the current research.

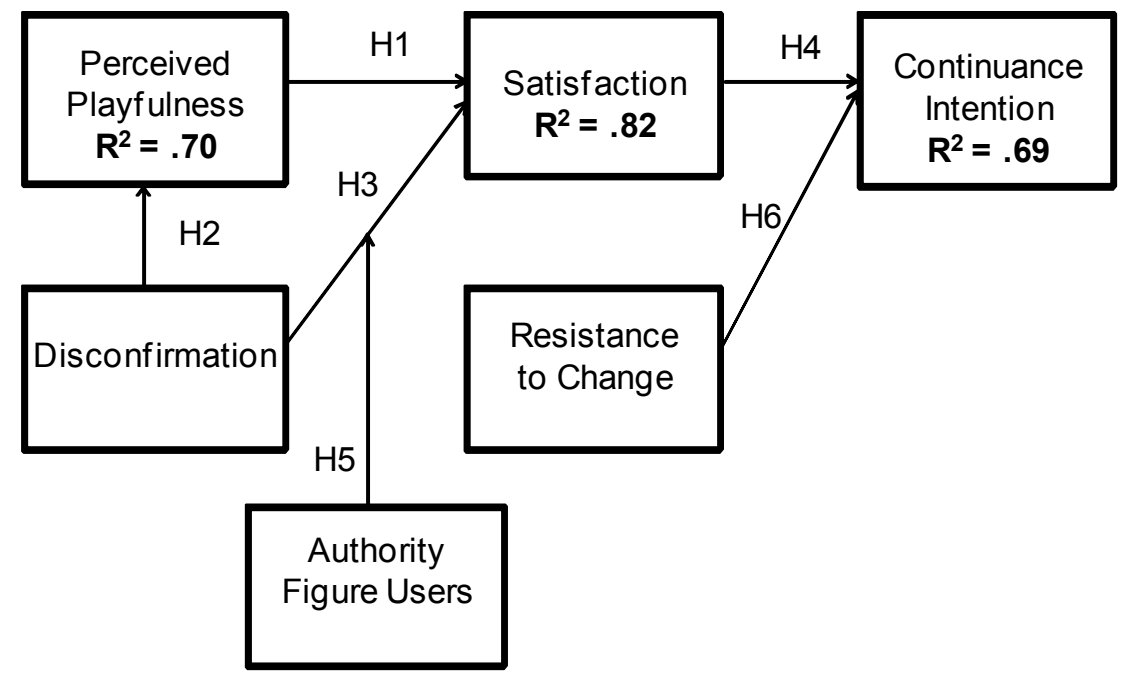

Figure 1. SNS Continuance Intention Model

Following the research of van der Heijden (2004) and Sledgianowski and Kulviwat (2009), perceived playfulness is defined as the level of enjoyment a user of an SNS believes using that site gives him/her. As mentioned previously, when investigating the use of an SNS, the measurement of intrinsic motivators in a hedonic context is appropriate rather than looking at utilitarian influences (Sledgianowski \& Kulviwat, 2009; van der Heijden, 2004). The research of this study will therefore focus on perceived playfulness, and proposes that:

H1: Perceived playfulness has a positive effect on a user's satisfaction with a SNS.

Disconfirmation is a construct that was emphasized by Oliver (1977) in his original ECT model and later by researchers who used ECT as their theoretical foundation (e.g., Bhattacherjee, 2001). It is a rare occurrence when an expectation is precisely confirmed or when a consumer gets exactly what was expected. Rather, it is more common that expectations are disconfirmed and found to be either better or worse than what was expected and the result can be either a positive disconfirmation where the user's experience was better than expected or a negative disconfirmation from an experience that was worse than expected, with a corresponding positive or negative effect on satisfaction. This research will follow prior ECT-based research in using disconfirmation as a construct that measures the extent to which a user's expectations were met and proposes the following hypotheses:

H2: Positive perceived playfulness has a positive effect on disconfirmation.

H3: Positive disconfirmation has a positive effect on a user's satisfaction with a SNS.

Many researchers have also conceptualized satisfaction with varying degrees of concurrence. Kim et al. (2009) and Bhattacherjee (2001) use a relatively convergent view of satisfaction in their respective studies on e-commerce, defining satisfaction as being a cognitive and affective state of fulfillment post-purchase. In a review of the literature on end-user system satisfaction, Au et al. 
(2002, p. 453) defined satisfaction as "the overall affective and cognitive evaluation of the pleasurable level of consumption-related fulfillment experienced with the IS."

This paper evaluates the overall satisfaction of SNS users, in which no purchase is made, but rather the site is used for hedonic purposes. Therefore, this research adopts a definition of satisfaction that incorporates elements of the above-mentioned definitions as well as modifying the definition to encompass the use of a SNS in a hedonic context. This study defines satisfaction as being the cognitive and affective state of emotion achieved by evaluating the experience of using an SNS as being pleasurable and proposes the following hypothesis:

H4: Satisfaction has a positive effect on intention to continue to use a SNS.

Authority figure user (AFU) is a developmental construct introduced in this study to determine the impact of these users on the satisfaction with the SNS by its original users - primarily college students in the case of Facebook. A new scale was developed and validated to effectively measure this exploratory construct. An in depth report of the complete survey measurement scale used in this research study will be discussed in the methodology section of this paper. AFU is defined in the context of this study as the perception of a new class of SNS users with the authority to exert disciplinary action such as parents, school administrators, law enforcement, or potential employers. As noted above, parents, school administrators, employers and even law enforcement officials now use SNSs to aid in their respective interests. Because of the many instances of punitive actions resulting from user posts that were discovered by AFU, it is theorized that as AFU awareness increases, the relationship between disconfirmation and satisfaction is thought to decrease, leading to the following hypothesis:

H5: The influence of disconfirmation on user satisfaction with the SNS is moderated by authority figure users such that as awareness of AFU increases, the satisfaction effect decreases.

Resistance to change (RTC) is another developmental construct introduced for the purpose of this study. As noted earlier, many instances of negative consequences can occur as a result of the SNS being used by certain classes of users that have evolved during the development of these sites. However, these negative consequences do not appear to have diminished the popularity of some SNSs, suggesting that there exists some resistance to changing their use of the SNS regardless of the undesirable effects of that use. This study defines RTC as the unwillingness of users to change their posting habits regardless of the types of new users on the SNS.

While it is proposed that AFU will have a negative moderating effect on the user's satisfaction with the SNS, it is suggested in this study that the resistance to change described above will supersede the dissatisfaction that arises from AFU. Noting that some SNSs continue to grow in popularity, despite apparent unwelcome classes of users on the sites as well as the consequences they bring, it is hypothesized that:

H6: Resistance to change will have a positive effect on intention to continue using the SNS.

\section{Methodology}

\section{Survey Development}

A written survey instrument was designed to test hypotheses H1 through H6 and was administered to college undergraduate students at a North American university. Cultural issues, the use of a student population, and the investigation exclusively of SNSs rather than other interactive communication technologies limit the generalizability of these results to other populations of SNS users. Previously validated scales were used where possible. Scales measuring disconfirmation, 
satisfaction, and continuance intention were taken from Bhattacherjee (2001) and perceived playfulness from Sledgianowski and Kulviwat (2009). Some of the scale items were used exactly as given, while some were adapted with slight modifications to better fit the context of this particular study.

Two of the constructs are developmental in nature and required the creation of new scale items for measurement: authority figure users (AFU) and resistance to change (RTC). AFU was measured by asking respondents if they had noticed new classes of users with various degrees of authority using their preferred SNS. Questions including "I noticed that more parents (ages 35-55) are using my SNS at an increasing rate" or "...school administrators..." or "law enforcement officials" or "potential employers" substituted separately were asked to determine if students had noticed a change in the demographics of users on their SNS. RTC was measured by items such as "An increasing rate of parents using my SNS won't change my posting habits," and so on. All items were rated on a 5-point Likert scale of $1=$ Strongly Agree to $5=$ Strongly Disagree. The survey instrument and a corresponding list of sources for scale items are included in the Appendix.

The survey was refined in several stages. First, five IS researchers reviewed the survey and provided comments as to the appropriateness and clarity of the survey instructions, questions, and layout. Modifications were made based on these comments. Next, the assistance of two faculty members was sought for further clarification of individual dimensions and questions used to measure the new constructs. Based upon the faculty feedback, refinements were made to the final survey instrument.

The modified survey instrument was administered to college undergraduate students at a North American university, primarily between the ages of 18-24. As this particular study focuses on satisfaction and continuance intentions with an SNS, students are an appropriate group for the survey, as they comprise a large percentage of the members. The respondents were selected from a convenience sample of two hundred and nine students, with thirteen of the responses being thrown out because of identical answers given for each question or because identical answers were given for two reverse coded items, indicating a violation of reliability of the answers given by those respondents. The resulting collection of usable responses to the survey was one hundred and ninety-six, or a $92 \%$ usable response rate.

The students were given a brief explanation of the purpose of the study: to measure their satisfaction with their preferred SNS and their intention to continue to use that site. Some of the respondents were offered extra credit at the discretion of their instructor. Some instructors chose not to offer any extra credit and some did. The response rate from the various classes was relatively high regardless of the offer.

\section{Results}

\section{Demographic Data}

Respondents were asked to list their gender, age, undergraduate year classification, and to list their preferred SNS, then answer specific questions only in regard to their preferred SNS. Demographic data includes a slight majority of males at $62 \%$ with the average age of users being 21 years. Additionally, the average number of "friends" in a student's network is 547 . The average number of times logging in to the SNS each day was 7 times and the average time spent on the SNS each day was 3 hours, with the results summarized in Table 1. The statistic that stands out is the overwhelming percentage of respondents who listed their preferred SNS as Facebook (95\%), while MySpace had only a small fraction of respondents. 


\begin{tabular}{|l|l|}
\hline \multicolumn{2}{|c|}{ Table 1: Descriptive Statistics } \\
\hline Gender & $62 \%$ Male \\
\hline Average Age & 21 years \\
\hline Classification & $63 \%$ Juniors \\
\hline Avg \# of Friends & 547 \\
\hline Avg \# Hours on SNS/day & 3 \\
\hline Avg \# Logins to SNS/day & 7 \\
\hline Preferred SNS & Facebook $-95 \%$ \\
\hline
\end{tabular}

\section{Assessing the Measurement Model}

Partial Least Squares (SmartPLS) was the appropriate tool for testing the model both because of the type of model and the limitations imposed by the sample size. PLS provides the ability to simultaneously examine the measurement model and the structural model. That is, the hypothesized relationships among the research constructs and the items to measure these constructs can be evaluated together. Additionally, PLS has a lower requirement for the minimal sample size (Chin, 1998).

Scale validation of the measurement model was performed with factor analysis to assess reliability and construct validity. Construct validity is established when both convergent and discriminant validity are demonstrated. Convergent validity provides a measure of the variance shared between a construct and its indicators. Convergent validity is assessed by examining whether items load with significant t-values of at least .05 on their corresponding construct (Gefen \& Straub, 2005). The rules of thumb used to support convergent validity include all factor loadings 0.50 or higher, and ideally 0.70 or higher (Hair, Black, Babin, Anderson, \& Tatham, 2006). Convergent validity was shown for each of the constructs in the measurement model with the resulting factor loadings shown in Table 2.

Following the guidelines of Hair et al. (2006), only those items with factor loadings higher than 0.70 were retained in the analysis. The factor loadings in this model for each of the constructs were well above 0.70 except for two developmental items. The survey item for AFU3, "I noticed that law enforcement officials are using my SNS at an increasing rate" loaded with a value of .548 and was therefore dropped from the analysis. It is possible that many students have simply not noticed law enforcement officials' activity on their preferred SNS. Additionally, the item for RTC4 ("An increasing rate of potential employers using my SNS won't change my posting habits") loaded with a value of .632 and likewise was removed from the analysis. Internal reliability of the resulting scale items is supported by composite reliability values that range from .88 to .99 , well above the recommended 0.7 or higher (Hair et al., 2006). This indicates adequate reliability of the measurement model. 


\begin{tabular}{|lllllll|}
\hline \multicolumn{7}{c}{ Table 2: Factor Loadings } \\
\hline & SAT & DISC & PP & CI & AFU & RTC \\
\hline Sat1 & $\mathbf{0 . 9 9}$ & 0.84 & 0.84 & 0.81 & 0.58 & 0.23 \\
Sat2 & $\mathbf{0 . 9 8}$ & 0.86 & 0.84 & 0.82 & 0.61 & 0.24 \\
Sat3 & $\mathbf{0 . 9 7}$ & 0.84 & 0.85 & 0.82 & 0.61 & 0.21 \\
\hline Disc1 & 0.77 & $\mathbf{0 . 9 1}$ & 0.74 & 0.69 & 0.50 & 0.16 \\
Disc2 & 0.74 & $\mathbf{0 . 9 3}$ & 0.74 & 0.70 & 0.44 & 0.15 \\
Disc3 & 0.87 & $\mathbf{0 . 9 3}$ & 0.83 & 0.78 & 0.62 & 0.26 \\
\hline PP1 & 0.84 & 0.82 & $\mathbf{0 . 9 6}$ & 0.80 & 0.57 & 0.19 \\
PP2 & 0.84 & 0.83 & $\mathbf{0 . 9 7}$ & 0.80 & 0.58 & 0.19 \\
PP3 & 0.77 & 0.75 & $\mathbf{0 . 9 4}$ & 0.73 & 0.49 & 0.15 \\
PP4 & 0.80 & 0.78 & $\mathbf{0 . 9 3}$ & 0.79 & 0.59 & 0.20 \\
\hline CI1 & 0.85 & 0.79 & 0.83 & $\mathbf{0 . 9 4}$ & 0.62 & 0.26 \\
CI2 & 0.79 & 0.77 & 0.78 & $\mathbf{0 . 9 3}$ & 0.59 & 0.29 \\
CI3 & 0.56 & 0.54 & 0.58 & $\mathbf{0 . 7 8}$ & 0.30 & 0.18 \\
CI4 & 0.65 & 0.61 & 0.64 & $\mathbf{0 . 8 3}$ & 0.48 & 0.23 \\
\hline AFU1 & 0.63 & 0.59 & 0.63 & 0.64 & $\mathbf{0 . 9 1}$ & 0.11 \\
AFU2 & 0.38 & 0.38 & 0.34 & 0.33 & $\mathbf{0 . 7 6}$ & 0.13 \\
AFU4 & 0.48 & 0.43 & 0.46 & 0.46 & $\mathbf{0 . 8 6}$ & 0.18 \\
\hline RTC1 & 0.23 & 0.22 & 0.22 & 0.28 & 0.19 & $\mathbf{0 . 9 0}$ \\
RTC2 & 0.23 & 0.20 & 0.17 & 0.28 & 0.16 & $\mathbf{0 . 9 4}$ \\
RTC3 & 0.16 & 0.14 & 0.12 & 0.18 & 0.06 & $\mathbf{0 . 8 8}$ \\
\hline
\end{tabular}

Convergent validity was determined by the high factor loadings mentioned above as well as by the measure of the average variance extracted (AVE) values which were all higher than the recommended .50 (Fornell \& Larcker, 1981). Discriminant validity was evaluated by comparing the square root of the AVE values (the average variance shared between the construct and its indicators) with the inter-construct correlations (the off-diagonal correlations) (Chin, 1998; Gefen \& Straub, 2005). Establishing discriminant validity requires that the square root of the AVE values should be higher than the correlation among any pair of latent constructs (Chin, 1998). In Table 3 , all of the square roots of the AVE values are higher than the off-diagonal values (interconstruct correlations). The composite reliabilities, AVE values and correlations are summarized in Table 3. The measurement model indicates strong construct validity with good measures of reliability and validity for the constructs in this model. This finding supports proceeding with the testing of the structural model. 


\begin{tabular}{|lllllllll|}
\hline \multicolumn{7}{c|}{ Table 3: Composite Reliability, AVE, and Correlations* } \\
& $\begin{array}{l}\text { Composite } \\
\text { Reliability }\end{array}$ & AVE & AFU & CI & DISC & PP & RTC & SAT \\
\hline AFU & 0.88 & 0.72 & $\mathbf{0 . 8 5}$ & & & & & \\
CI & 0.93 & 0.76 & 0.59 & $\mathbf{0 . 8 7}$ & & & & \\
DISC & 0.94 & 0.85 & 0.57 & 0.79 & $\mathbf{0 . 9 2}$ & & & \\
PP & 0.97 & 0.90 & 0.59 & 0.82 & 0.84 & $\mathbf{0 . 9 5}$ & & \\
RTC & 0.93 & 0.82 & 0.16 & 0.28 & 0.21 & 0.19 & $\mathbf{0 . 9 1}$ & \\
SAT & 0.99 & 0.96 & 0.61 & 0.83 & 0.86 & 0.86 & 0.23 & $\mathbf{0 . 9 8}$ \\
\hline
\end{tabular}

*The bold values on the diagonal are the square roots of the average variance extracted $(\mathrm{AVE})$ value. The off-diagonal values are correlations between latent constructs.

\section{Assessing the Structural Model}

The next step of the analysis involved testing the structural model to determine what evidence exists in the data to support the hypotheses. In this study, the investigation of the hypotheses was conducted using Partial Least Squares (PLS) to test the fit of the structural model. PLS is an advanced statistical method that allows examining and testing the structural path (Chin, 1998). PLS has a lower requirement in terms of the minimal sample size, measurement scales, and distribution assumptions than covariance-based SEM approaches such as LISREL (Chin, 1998). PLS is a variance-based SEM methodology that was expanded into marketing and social science research (Hair et al., 2006). The PLS analysis yielded path coefficients for the structural model that allowed testing the strength of the relationship between the independent and dependent variables. The levels of significance were estimated using t-statistics derived from a bootstrapping procedure with 600 re-samples. $\mathrm{R}^{2}$ values provide a measure of the model's predictive power for the dependent variables and were also obtained in the PLS analysis. The $\mathrm{R}^{2}$ value indicates the total percentage of variation of continuance intention explained by the research model. Figure 2 shows the resulting $\mathrm{R}^{2}$ values and path coefficients of the various relationships hypothesized in the model.

The structural model showed that each of the six hypotheses was supported and an overall $\mathrm{R}^{2}$ for continuance intentions of $69 \%$. Perceived playfulness showed a significant positive relationship with satisfaction, with a path coefficient of .396 and thus supporting H1. Disconfirmation also had a significant positive relationship with perceived playfulness, with a coefficient of .838 and therefore supporting H2. Disconfirmation also revealed a significant positive relationship with satisfaction, having a path coefficient of .679 and thus supporting H3. These findings extend the support for the use of ECT when investigating user satisfaction of an IS (Abdinnour-Helm et al., 2005; Kim et al., 2009; McKinney et al., 2002).

Satisfaction had a significant positive relationship with continuance intention, with a coefficient of .809 and therefore H4 is also supported. Again, this finding supports the synthesis of ECT and continuance intentions (Bhattacherjee, 2001). The hypothesis dealing with the new AFU construct was $\mathrm{H} 5$, and the results showed that the moderating variable of $\mathrm{AFU} *$ disconfirmation has a significant negative moderating effect on satisfaction with a coefficient of -..351, and thus $\mathrm{H} 5$ is supported. The new construct of RTC showed a significant positive relationship to continuance intentions with a coefficient of .093, thus supporting H6. All relationships were significant at the alpha $(\alpha)<.05$ level, with alpha being the significance level associated with the statistical testing of the differences among the variables. 
Harden, Ryan, \& Prybutok

SNS Continuance Intention Model

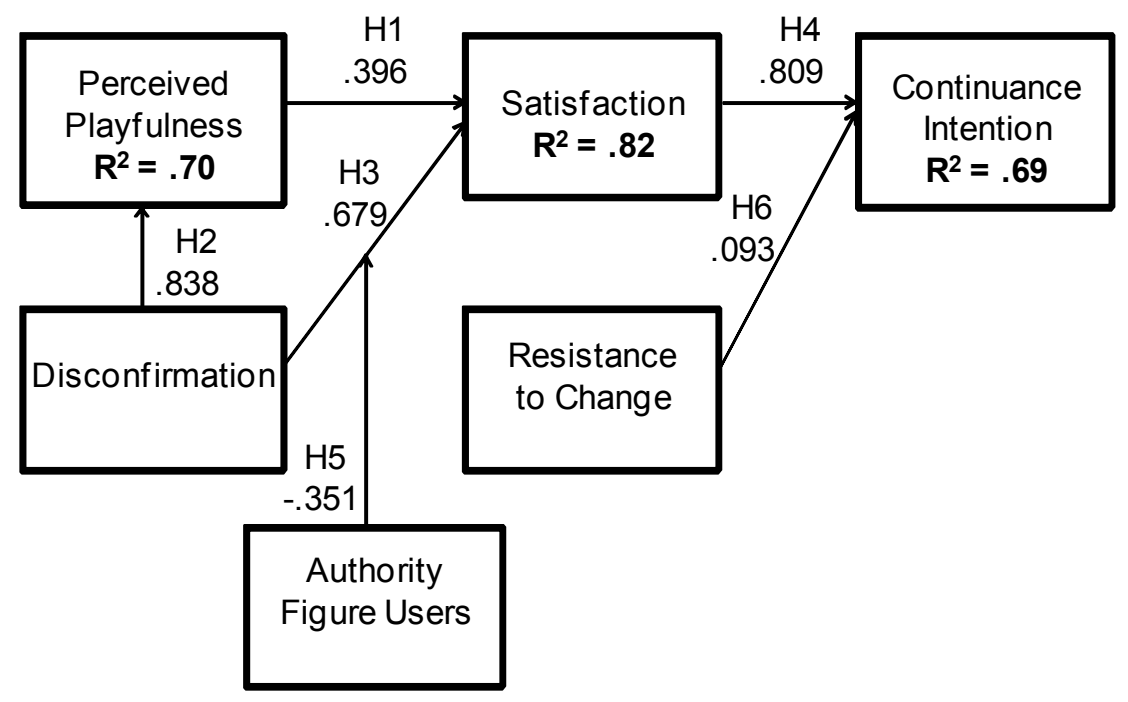

Figure 2: SNS Continuance Intention Model, Path Coefficients, and $\mathbf{R}^{2}$ Values

The results indicate that perceived playfulness and the moderating effect of authority figure users have conflicting influences on satisfaction when measuring SNS experiences. Additionally, a new predictor of continuance intentions - RTC - is supported by the data, indicating that a certain resistance to changes that may even be unsatisfactory can retain the intention to continue using the SNS. Table 4 summarizes the hypotheses and their corresponding result according to the data collected in this study.

\section{Table 4: Hypotheses Summary}

\begin{tabular}{|l|l|}
\hline $\begin{array}{l}\text { H1: Perceived playfulness will have a positive effect on a user's satis- } \\
\text { faction with a SNS. }\end{array}$ & Supported \\
\hline $\begin{array}{l}\text { H2: Positive perceived playfulness will have a positive effect on dis- } \\
\text { confirmation. }\end{array}$ & Supported \\
\hline $\begin{array}{l}\text { H3: Positive disconfirmation will have a positive effect on a user's } \\
\text { satisfaction with a SNS. }\end{array}$ & Supported \\
\hline $\begin{array}{l}\text { H4: Higher levels of satisfaction will have a positive effect on inten- } \\
\text { tion to continue to use a SNS. }\end{array}$ & Supported \\
\hline $\begin{array}{l}\text { H5: Authority figure users will have a negative moderating effect on } \\
\text { user satisfaction with the SNS. }\end{array}$ & Supported \\
\hline $\begin{array}{l}\text { H6: Resistance to change will have a positive effect on intention to } \\
\text { continue using the SNS. }\end{array}$ & Supported \\
\hline
\end{tabular}




\section{Discussion}

The results show that an empirically tested new construct, authority figure users, has a negative moderating effect on the relationship between disconfirmation and satisfaction. That is, the more respondents noticed that authority figures were using their SNS, despite other expectations being met (confirmed), the lower their satisfaction. Prior research investigating student reactions to friend requests from authority figures such as professors, parents, and employers found that students had the most positive reactions to friend requests from their mother or boss (Karl \& Peluchette, 2011). These results seem to support the notion that some authority figure users pose more concern than others to students. Rambe and Ng'ambi (2011) also report a tendency for students to be wary of participating in Facebook informing environments created between educators and learners, as confusion can arise regarding the purpose of such roles in a social informing environment. While Cohen (2009) noted that informing takes place in a complex environment, the informing environment of Facebook and other SNSs bring even more complex issues as the roles of informer and client are blurred.

The perceived playfulness construct, which is the fun, enjoyment, or entertainment value of using the SNS, was also significantly related to satisfaction. The data support the contention that while the awareness of the new authority figure users changes the satisfaction that college age users indicate they feel, it is partially offset by the perceived playfulness they experience from using the SNS. The explosion of games on Facebook has provided users with entertainment above and beyond conversing with friends or acquaintances ("What Americans do online," 2010). The gaming aspect of social networks has become so large that Facebook is expected to generate $\$ 1$ billion in revenue in 2011 from social gaming (Kushner, 2011).

In terms of continuance intention, both satisfaction and resistance to change have a significant impact. The influence of satisfaction on continuance intention is consistent with prior ECT research. However, the resistance to change construct provides a partial explanation of why an SNS like Facebook can continue to grow even when some of its users are not completely satisfied with part of their experience using the site.

\section{Implications}

This study contributes to the informing science framework with the finding that in the SNS informing environment, the status of the informer and the fact that clients and informers can assume each other's roles has a significant effect on satisfaction and continuance intention. The complexity involved in the SNS informing system has a significant influence on informing in terms of the sender's message being received by the client and understood as intended, increasing the challenge of effective informing (Gill \& Cohen, 2008). The fact that clients and informers can assume each other's roles only increases the complexity when authority figure users enter the informing environment. The results of the study help explain the dissatisfaction that arises in the client and, also, how that dissatisfaction can be offset by a resistance to change.

The implications of the current study for practitioners include a better understanding of how users react to changes in their SNS that lower their satisfaction because of new demographics of users and/or uses of the SNS. Authority figure users might send one group of current users off in search of an SNS where they do not feel threatened by the changing users or uses. However, resistance to change is a factor that influences the user to remain even when they are unhappy with the changes of the current SNS. Developers of SNS sites must be aware of the entrance of more SNS options for their existing users to choose from, such as Google+, and the potential threat posed if the new sites gain informers and clients that are important to the current users. The dissatisfaction 
of users in the past has sent more than one SNS on a downward spiral as the existing users migrated to a new SNS platform.

\section{Limitations and Future Research}

Limitations of this study include the examination of an online system in the purely hedonic context of a SNS. While research is beginning to examine the use of SNSs such as Facebook for educational endeavors (Brahmasrene \& Lee, 2012; Buzzetto-More, 2012), the current research is focused purely on the entertainment, or hedonic use of these networks. However, the results can be generalized to other online systems in future studies if one looks at perceived usefulness rather than perceived playfulness as Bhattercherjee (2001) did.

Another limitation includes the use of only college students at a North American university using Facebook and MySpace when measuring level of satisfaction and SNS continuance intention. While appropriate in the context of this study, as this particular demographic was the original intended audience for Facebook and largely for MySpace as well, better generalizability could be gained by performing the same study on a more diverse group of participants, such as students in other countries with different cultural values. Another suggestion for future research is a study of eBay, a utilitarian site of users who have seen their site used more and more frequently by commercial businesses rather than individual sellers.

While this research helps explain the paradox of an SNS environment continuing to grow despite unfavorable outcomes, it does not address why a site like MySpace was unable to do so when dissatisfaction crept into its user base. One potential explanation is the concept of critical mass. Critical mass has been defined as the point where enough users have adopted the innovation to make it self-sustaining (Sledgianowski \& Kulviwat, 2009; Van Slyke, Ilie, Lou, \& Stafford, 2007). When evaluating the potential benefit from using an SNS, clients will consider the importance of other informers that can contribute to their experience. Obviously, in order for there to be a community to share experiences with, there must be a certain number of users participating.

The concept of critical mass might be one reason why users would want to continue using the SNS even with the addition of authority figure users that has a negative moderating effect on their satisfaction. As long as the mass of users remain who are important to the SNS members, their emotional investment in the relationships that are created and maintained through the site is likely strengthened. Future research should explore the concept of critical mass to understand more fully this apparent paradox.

Further efforts to understand why an informing SNS such as Facebook continues to grow in size and popularity, even with numerous reports of unfavorable consequences related to using the site, require transdisciplinary research in fields of study that deal with understanding cognitive, behavioral, and social issues (Cohen, 2009). Many social networking sites such as Facebook, MySpace, Twitter, and YouTube are instantly recognizable and their impact on individual behavior has been increasingly examined (Dwyer, Hiltz, \& Passerini, 2007; Harden, 2010; Kreps, 2010; Shi, Lee, Cheung, \& Chen, 2010). However, current research has not yet been able to explain possible reasons for an SNS such as MySpace, which once seemed unstoppable in its growth and popularity, suddenly to slash its workforce and search for a buyer as it continued to lose members.

Further, as baby-boomers begin to leave the workforce in growing numbers, they will take with them critical amounts of "tacit knowledge, operational heuristics, stories and organizational history," (Jackson, 2010, p. 908). Jackson's (2010) research proposes that delivery systems using social media such as SNSs in the workplace can be an effective and inexpensive way to capture, store, structure, share, and maintain that knowledge. Enterprise use of an SNS informing environment can also offer the benefit of providing the tools expected in the workplace of a younger workforce accustomed to such levels of connectivity and interactivity. With the imminent entry of 
SNSs into daily personal as well as professional lives, both in a hedonic and a utilitarian context, future research aimed at understanding users' satisfaction and continuance intentions with these informing systems is warranted.

\section{Conclusion}

The goal of this study was to determine what effect the addition of authority figure users has on the satisfaction of the original SNS users and, thus, their intention to continue using that site. Using data collected from a survey of college students, the results show that a new construct introduced in this study, authority figure users, has a significant negative moderating effect on satisfaction. However, the other new construct introduced in this study, resistance to change, indicates that SNS users feel some resistance to changing their posting habits, regardless of the addition of AFU as a new set of users. In this sense, their resistance actually insulates them to unsatisfactory consequences and serves as a positive influence on their intention to continue using the SNS. This conceptualization of RTC as a psychological construct explains the continuance intentions of SNS users in the face of potential unsatisfactory developments in the use of their SNS. Such a relationship needs further trandisciplinary research to understand more clearly the psychological fragilities of the clients in SNS informing environments (Cohen, 2009).

This study extends the research efforts of online informing systems that use ECT and IS continuance theory in explaining satisfaction with an online IS and the resulting continuance intentions of its users. In addition, this research supports the findings of others that perceived playfulness is a significant predictor of satisfaction or intent to use an online system in a hedonic context (Sledgianowski \& Kulviwat, 2009; van der Heijden, 2004). Still, further transdisciplinary research on the informing environments of an SNS is necessary to understand more fully the various motivators of users' continuance intentions. Although beyond the scope of the current study, a future research effort might undertake a more in depth examination of other factors that influence continuance intention such as social presence or privacy issues which could be added to the model to determine their effect, as has been suggested by other researchers (Boyd \& Ellison, 2007; Dwyer et al., 2007). Efforts that explore the concept of critical mass and the effect it can have on satisfaction and continuance intentions of various online IS users is also another avenue for future research, including within the organization. Clearly, the concept of social networking in online informing environments for a variety of purposes has become commonplace and informing science research should continue to examine the phenomenon.

\section{References}

Abdinnour-Helm, S., Chaparro, B., \& Farmer, S. (2005). Using the end-user computing satisfaction (EUCS) instrument to measure satisfaction with a web site. Decision Science, 36(2), 341-364.

Arango, T. (2009, June 16). MySpace set to lay off 400 Workers. The New York Times. Retrieved March 12,2012 , from http://www.nytimes.com/2009/06/17/technology/companies/17myspace.html?scp=14\&sq=arango\%20 $\underline{\text { myspace\&st }=\text { cse }}$

Arango, T. (2011, January 11). Hot social networking site cools as Facebook grows. The New York Times, Retrieved March 12, 2012, from http://www.nytimes.com/2011/01/12/technology/internet/12myspace.html?scp=2\&sq=arango $\% 20$ mys pace $\&$ st $=$ cse

Au, N., Ngai, E., \& Cheng, T. (2002). A critical review of end-user system satisfaction: Research and a new research framework. Journal of Management Science, 30, 451-478.

Bhattacherjee, A. (2001). Understanding information systems continuance: An expectation-confirmation model. MIS Quarterly, 25(3), 351-370. 
Bhattacherjee, A., \& Premkumar, G. (2004). Understanding changes in belief and attitude toward information technology usage: A theoretical model and longitudinal test. MIS Quarterly, 28(2), 229-254.

Birdsall, F. W. (2009). The role of the client in informing science: To be informed and to inform. Informing Science: the International Journal of an Emerging Transdiscipline. 12, 147-157. Retrieved March 12, 2012, from http://www.inform.nu/Articles/Vol12/ISJv12p147-157Birdsall535.pdf

Boyd, D., \& Ellison, N. (2007). Social network sites: Definition, history, and scholarship. Journal of Computer-Mediated Communication, 13(1), 210-230.

Brahmasrene, T., \& Lee, J. (2012). Determinants of intent to continue using online learning: A tale of two universities. Interdisciplinary Journal of Information, Knowledge, and Management, 7, 1-20. Retrieved August 30, 2012 from http://www.ijikm.org/Volume7/IJIKMv7p001-020Brahmasrene540.pdf

Brown, S., Venkatesh, V., Kuruzovich, J., \& Massey, A. (2008). Expectation confirmation: An examination of three competing models. Organizational Behavior and Human Decision Processes, 105, 52-66.

Buzzetto-More, N. (2012). Social networking in undergraduate education. Interdisciplinary Journal of Information, Knowledge, and Management, 7, 63-90. Retrieved August 30, 2012 from http://www.ijikm.org/Volume7/IJIKMv7p063-090Buzzetto611.pdf

Chen, I. (2007). The factors influencing members' continuance intentions in professional virtual communities - a longitudinal study. Journal of Information Science, 33(4), 451-467.

Chin, W. W. (1998). Issues and opinion on structural equation modeling. MIS Quarterly, 22(1), vii-xvi.

Cohen, E. B. (2009). A philosophy of informing science. Informing Science: the International Journal of an Emerging Transdiscipline, 12, 1-15. Retrieved March 25, 2012, from http://www.inform.nu/Articles/Vol12/ISJv12p001-015Cohen399.pdf

comScore [Press Release]. (2009). Media Metrix ranks top 50 U.S. web properties for April 2009. Retrieved March 12, 2012, from http://www.comscore.com/Press_Events/Press_Releases/2009/5/Social_Networking_Category_Has_R ecord_Month_Led by_Gains at Twitter_and_Facebook/(language)/eng-US

Cross-Tab. (2010). Online reputation in a connected world. Cross-Tab Marketing Services white paper, sponsored by Microsoft. Retrieved March 12, 2012, from http://go.microsoft.com/?linkid=9709510

Davis, F. (1989). Perceived usefulness, perceived ease of use, and user acceptance of information technology. MIS Quarterly, 13(3), 319-340.

Dwyer, C., Hiltz, S., \& Passerini, K. (2007). Trust and privacy concern within social networking sites: A comparison of Facebook and MySpace. Proceedings of the Thirteenth Americas Conference on Information Systems, 1-12.

Facebook helps police arrest 74. (2010, November 5). UPI. Retrieved March 16, 2012, from http://www.upi.com/Odd_News/2010/11/05/Facebook-helps-police-arrest-74/UPI-24251288992799/

Facebook Company Info. (2005, December). Timeline. Retrieved October 15, 2012, from http://newsroom.fb.com/content/default.aspx?NewsAreaId=20

Facebook Company Info. (2011, November 6). Timeline. Retrieved October 15, 2012, from http://newsroom.fb.com/content/default.aspx?NewsAreaId=20

Fornell, C., \& Larcker, D. (1981). Evaluating structural equation models with unobservable variables and measurement error. Journal of Marketing Research, 18, 39-50.

Gill, T. G., \& Cohen, E. B. (2008). Research themes in complex informing. Informing Science: the International Journal of an Emerging Transdiscipline, 11, 147-165. Retrieved March 15, 2012, from http://www.inform.nu/Articles/Vol11/ISJv11p147-164GillIntro.pdf

Gefen, D., \& Straub, D. (2005). A practical guide to factorial validity using PLS-Graph: Tutorial and annotated example. Communications of the AIS, 16, 91-109. 
Greiner, A. (2010, February). Student suspended for Facebook teacher slam. NBCChicago.com. Retrieved August 28, 2012, from http://www.nbcchicago.com/news/local-beat/Student-Suspended-for-FacebookFan-Page-84958567.html

Hair, J. F., Black, W. C., Babin, B. J., Anderson, R., \& Tatham, R. L. (2006). Multivariate data analysis (6th ed.). New Jersey: Pearson Education.

Harden, G. (2010). Satisfaction with social networking sites: Effect of playfulness and change in use. Proceedings of the Sixteenth Americas Conference on Information Systems. Paper 101.

Hess, T., Joshi, K., \& McNab, A. (2010). An alternative lens for understanding technology acceptance: An equity comparison perspective. Journal of Organizational Computing and Electronic Commerce, 20(2), 123.

Jackson, P. (2010). Capturing, structuring, and maintaining knowledge: A social software approach. Industrial Management and Data Systems, 110(6), 908-929.

Joshi, K. (2005). Understanding user acceptance and resistance during the implementation of an order management system: A case study using equity implementation model. Journal of Information Technology Case and Application Research, 7(1), 6-20.

Karl, K. A., \& Peluchette, J. V. (2011). 'Friending' professors, parents and bosses: A Facebook connection conundrum. Journal of Education for Business, 86(4), 214-222.

Kim, D., Ferrin, D., \& Rao, H. (2009). Trust and satisfaction, two stepping stones for successful ecommerce relationships: A longitudinal exploration. Information Systems Research, 20(2), 237-257.

Kreps, D. (2010). My social networking profile: Copy, resemblance, or simulacrum? A poststructuralist interpretation of social information systems. European Journal of Information Systems, 19(1), 104.

Kushner, D. (2011). Betting the farm on games. IEEE Spectrum, 48(6), 70-88.

Levy, A. (2009, February). Teenager office worker sacked for moaning about her 'totally boring' job. Mail Online. Retrieved August 28, 2012 from http://www.dailymail.co.uk/news/article-1155971/Teenageoffice-worker-sacked-moaning-Facebook-totally-boring-job.html

Lin, C., Wu, S., \& Tsai, R. (2005). Integrating perceived playfulness into expectation-confirmation model for web portal context. Information \& Management, 42(5), 683-693.

McKinney, V., Yoon, K., \& Zahedi, F. (2002). The measurement of web-customer satisfaction: An expectation and disconfirmation approach. Information Systems Research, 13(3), 296-325.

Milian, M. (2012, January 19). Google says social network has 90M users. CNN Online. Retrieved March 16, 2012, from http://articles.cnn.com/2012-01-19/tech/tech_social-media_google-plususers 1 search-engine-social-network-results-pages? $s=$ PM:TECH

Oliver, R. (1977). Effect of expectation and disconfirmation on postexposure product evaluations: An alternative interpretation. Journal of Applied Psychology, 62(4), 480-486.

Oreg, S. (2006). Personality, context, and resistance to organizational change. European Journal of Work \& Organizational Psychology, 15(1), 73-101.

ProofPoint. (August 10, 2009). Careful what you email, post, upload and tweet: US businesses embrace aggressive preventative measures. Retrieved March 16, 2012, from http://www.proofpoint.com/aboutus/press-releases/08102009.php

Rambe, P., \& Ng'ambi, D. (2011). Towards an information sharing pedagogy: A case of using Facebook in a large first year class. Informing Science: the International Journal of an Emerging Transdiscipline, 14, 62-89. Retrieved March 12, 2012, from http://www.inform.nu/Articles/Vol14/ISJv14p061089Rambe579.pdf

Shi, N., Lee, M., Cheung, C., \& Chen, H. (2010). The continuance of online social networks: How to keep people using Facebook? 43rd Hawaii International Conference on System Sciences, pp. 1-10. 
Sledgianowski, D., \& Kulviwat, A. (2009). Using social network sites: The effects of playfulness, critical mass and trust in a hedonic context. The Journal of Computer Information Systems, 49(4), 74-84.

Srivastava, A. (2011). Resistance to change: Six reasons why businesses don't use e-signatures. Electronic Commerce Research, 11(4), 357-382.

Stelter, B. (2011, June 29). News Corporation sells MySpace for \$35 million. The New York Times, Retrieved March 16, 2012, from http://mediadecoder.blogs.nytimes.com/2011/06/29/news-corp-sellsmyspace-to-specific-media-for-35-million/?ref=myspacecom

Student suspended over Facebook post. (2011, October 14). UPI. Retrieved August 24, 2011, from http://www.upi.com/Odd_News/2011/10/14/Student-suspended-over-Facebook-post/UPI$\underline{31411318579200 /}$

Sullivan, D. (2011, June 28). Google's Facebook competitor, the Google+ social network, finally arrives. Retrieved March 16, 2012, from http://searchengineland.com/googles-facebook-competitor-thegoogle-social-network-finally-arrives-83401

Szajna, B., \& Scamell, R. (1993). The effects of information system user expectations on their performance and perceptions. MIS Quarterly, 17(4), 493-516.

TechCrunch. (n.d.). CrunchBase - MySpace. Retrieved October 15, 2012, from http://www.crunchbase.com/company/myspace

Towards a socialized state: The joy of unlimited communication. (2010, January 28). The Economist. Retrieved August 28, 2012 from http://www.economist.com/node/15350960

van der Heijden, H. (2004). User acceptance of hedonic information systems. MIS Quarterly, 28(4), 695704.

Van Slyke, C., Ilie, V., Lou, H., \& Stafford, T. (2007). Perceived critical mass and the adoption of a communication technology. European Journal of Information Systems, 16(3), 270-283.

Vatanasombut, B., Igbaria, M., Stylianou, A., \& Rodgers, W. (2008). Information systems continuance intention of web-based applications customers: The case of online banking. Information \& Management, 45, 419-428.

Venkatesh, V., Morris, M., Davis, G., \& Davis, F. (2003). User acceptance of information technology: Toward a unified view. MIS Quarterly 27(3), 425-478.

Wixom, H., \& Todd, P.A. (2005). A theoretical integration of user satisfaction and technology acceptance. Information Systems Research, 16(1), 85-102.

What Americans do online: Social media and games dominate activity. (2010, August 2). NielsenWire. Retrieved March 16, 2012, from http://blog.nielsen.com/nielsenwire/online mobile/what-americansdo-online-social-media-and-games-dominate-activity/ 


\section{Appendix}

\begin{tabular}{|c|c|c|}
\hline & \multicolumn{2}{|l|}{ Appendix A: Survey Items and Sources } \\
\hline CONSTRUCT & SCALE ITEM & SOURCE \\
\hline \multirow{4}{*}{$\begin{array}{l}\text { Perceived } \\
\text { Playfulness }\end{array}$} & PP1) Using my SNS gives me enjoyment. & $\begin{array}{l}\text { Sledgianowski \& } \\
\text { Kulviwat } 2009\end{array}$ \\
\hline & PP2) Using my SNS is fun for me. & $\begin{array}{l}\text { Sledgianowski \& } \\
\text { Kulviwat } 2009\end{array}$ \\
\hline & PP3) Using my SNS makes me happy. & $\begin{array}{l}\text { Sledgianowski \& } \\
\text { Kulviwat } 2009 \\
\end{array}$ \\
\hline & PP4) Using this website is entertaining to me. & $\begin{array}{l}\text { Sledgianowski \& } \\
\text { Kulviwat } 2009 \\
\end{array}$ \\
\hline \multirow{3}{*}{$\begin{array}{l}\text { Disconfirma- } \\
\text { tion }\end{array}$} & $\begin{array}{l}\text { D1) My experience with using my SNS was better than I } \\
\text { expected. }\end{array}$ & $\begin{array}{l}\text { Bhattacherjee } \\
2001\end{array}$ \\
\hline & $\begin{array}{l}\text { D2) The benefits provided to me by my SNS are better than } \\
\text { what I expected. }\end{array}$ & $\begin{array}{l}\text { Bhattacherjee } \\
2001\end{array}$ \\
\hline & $\begin{array}{l}\text { D3) Overall, most of my expectations from using my SNS } \\
\text { were confirmed. }\end{array}$ & $\begin{array}{l}\text { Bhattacherjee } \\
2001\end{array}$ \\
\hline \multirow{3}{*}{ Satisfaction } & $\begin{array}{l}\text { S1) I feel very satisfied with my overall experience using } \\
\text { my SNS. }\end{array}$ & $\begin{array}{l}\text { Bhattacherjee } \\
2001\end{array}$ \\
\hline & $\begin{array}{l}\text { S2) I feel very pleased with my overall experience of using } \\
\text { my SNS. }\end{array}$ & $\begin{array}{l}\text { Bhattacherjee } \\
2001\end{array}$ \\
\hline & $\begin{array}{l}\text { S3) I feel very contented with my overall experience using } \\
\text { my SNS. }\end{array}$ & $\begin{array}{l}\text { Bhattacherjee } \\
2001\end{array}$ \\
\hline \multirow{4}{*}{$\begin{array}{l}\text { Continuance } \\
\text { Intention }\end{array}$} & $\begin{array}{l}\text { CI1) I intend to continue using my current SNS rather than } \\
\text { discontinue using it. }\end{array}$ & $\begin{array}{l}\text { Bhattacherjee } \\
2001\end{array}$ \\
\hline & $\begin{array}{l}\text { CI2) My intentions are to continue using my current SNS } \\
\text { rather than use an alternate SNS. }\end{array}$ & $\begin{array}{l}\text { Bhattacherjee } \\
2001\end{array}$ \\
\hline & $\begin{array}{l}\text { CI3) I would not consider discontinuing the use of my cur- } \\
\text { rent SNS. }\end{array}$ & $\begin{array}{l}\text { Bhattacherjee } \\
2001\end{array}$ \\
\hline & CI4) I would like to discontinue the use of my current SNS. & $\begin{array}{l}\text { Bhattacherjee } \\
2001\end{array}$ \\
\hline \multirow{4}{*}{$\begin{array}{l}\text { Authority } \\
\text { Figure User }\end{array}$} & $\begin{array}{l}\text { AFU1) I noticed that more parents (ages } 35-55 \text { ) are using } \\
\text { my SNS at an increasing rate. }\end{array}$ & Developmental \\
\hline & $\begin{array}{l}\text { AFU2) I noticed that more school administrators are using } \\
\text { my SNS at an increasing rate. }\end{array}$ & Developmental \\
\hline & $\begin{array}{l}\text { *AFU3) I noticed that law enforcement officials are using } \\
\text { my SNS at an increasing rate. }\end{array}$ & Developmental \\
\hline & $\begin{array}{l}\text { AFU4) I noticed that potential employers are using my } \\
\text { SNS at an increasing rate. }\end{array}$ & Developmental \\
\hline \multirow{4}{*}{$\begin{array}{l}\text { Resistance to } \\
\text { Change }\end{array}$} & $\begin{array}{l}\text { RTC1) An increasing rate of parents using my SNS won't } \\
\text { change my posting habits on my SNS. }\end{array}$ & Developmental \\
\hline & $\begin{array}{l}\text { RTC2) An increasing rate of school administrators using } \\
\text { my SNS won't change my posting habits on my SNS. }\end{array}$ & Developmental \\
\hline & $\begin{array}{l}\text { RTC3) An increasing rate of law enforcement officials us- } \\
\text { ing my SNS won't change my posting habits on my SNS. }\end{array}$ & Developmental \\
\hline & $\begin{array}{l}\text { *RTC4) An increasing rate of potential employers using } \\
\text { my SNS won't change my posting habits on my SNS. }\end{array}$ & Developmental \\
\hline
\end{tabular}

*Item dropped from analysis. 


\section{Biographies}

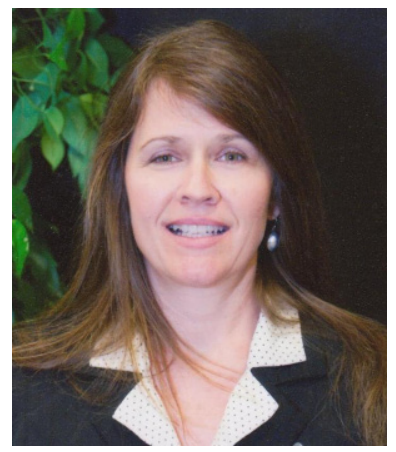

Gina Harden is a $\mathrm{PhD}$ candidate in Information Systems at the University of North Texas and received her MBA in Management from the University of Texas at Tyler. Her primary areas of research interest include social networking, knowledge sharing, and social media. Her work has appeared in the journal of IEEE Transactions on Professional Communications, Proceedings of the Hawaii International Conference on System Sciences, Proceedings of Decision Science Institute and Proceedings of the Americas Conference on Information Systems.

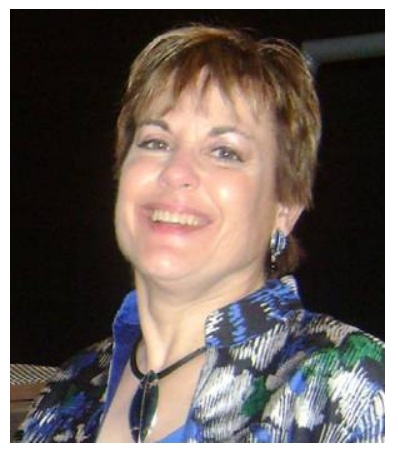

Sherry D. Ryan is an Associate Professor of Information Technology and Decision Sciences at the University of North Texas. She received her Ph.D. in IS from the University of Texas at Arlington and an MBA from the University of Southern California. Prior to returning to academia she worked for IBM, teaching courses and speaking at national conferences. Her research interests include IT human resource issues, knowledge management, and social media. Her work has appeared in journals including Journal of Management Information Systems, Decision Support Systems, and Informing Science: the International Journal of an Emerging Transdiscipline.

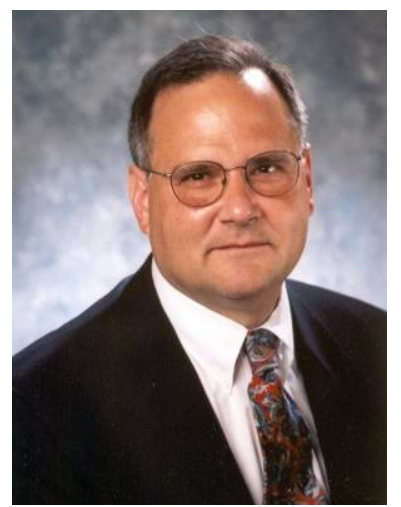

Victor R. Prybutok is a Regents Professor of Decision Sciences in the Information Technology and Decision Sciences Department and Associate Dean of the Toulouse Graduate School at the University of North Texas. He received, from Drexel University, his B.S. with High Honors in 1974, a M.S. in Bio-Mathematics in 1976, a M.S. in Environmental Health in 1980, and a Ph.D. in Environmental Analysis and Applied Statistics in 1984. Dr. Prybutok is an American Society for Quality certified quality engineer, certified quality auditor, certified manager of quality / organizational excellence, and an accredited professional statistician (PSTAT ${ }^{\circledR}$ ) by the American Statistical Association. Dr. Prybutok has authored over 125 journal articles, several book chapters, and more than 130 conference presentations in information systems measurement, quality control, risk assessment, and applied statistics. 